\section{LA AFASIA EN LOS TESTIMONIOS DE CONVERSIÓN SÚBITA}

\author{
José María Contreras Espuny \\ Universidad de Sevilla \\ josemariacontrerasespuny@gmail.com \\ http://orcid.org/0000-0001-8813-8474
}

Cómo citar este artículo/Citation: Contreras Espuny, J. M. (2017). La afasia en los testimonios de conversión súbita. Arbor, 193 (783): a374. doi: http://dx.doi.org/10.3989/ arbor.2017.783n1005

Recibido: 11 mayo 2015. Aceptado: 25 octubre 2015.

RESUMEN: Mediante el estudio comparativo filológico y fenomenológico de los testimonios autógrafos de conversión súbita de Paul Claudel, Manuel García Morente y André Frossard, se pretende indagar en la afasia, entendida como incapacidad de hablar frente a la teofanía y la dificultad de comunicar está en un marco testimonial. En comparación con la tradición mística, se hará un recorrido por la taxonomía de lo inefable en el corpus y se observarán sus posibilidades lingüísticas y narrativas. El objetivo es analizar los rasgos e implicaciones que adquiere el lenguaje a la hora de tener que comunicar un algo inexpresable, en este caso, la aparición puntual de la divinidad con las implicaciones místicas que conlleva.

PALABRAS CLAVE: lo inefable; afasia; conversión súbita; autobiografía; escritura.

\section{APHASIA IN SUDDEN CONVERSION TESTIMONIES}

Copyright: (c) 2017 CSIC. Este es un artículo de acceso abierto distribuido bajo los términos de la licencia Creative Commons Attribution (CC BY) España 3.0.

ABSTRACT: By means of the comparative philological and phenomenological studies of the autobiographical testimonies of Paul Claudel, Manuel García Morente and André Frossard, we inquire into aphasia, an incapacity to talk compared with theophany and the difficulty, when the time comes, to communicate this in a testimonial setting. By comparing this to the mystic tradition, we explore the taxonomy of the ineffable fact in the corpus, as well as the linguistic and narrative possibilities. The aim is to analyse the features and implications of the language when it has to communicate the inexpressible, in this case, one-time appearance of the deity, considering the mystic implications involved.

KEYWORDS: ineffable; aphasia; sudden conversion; autobiography; writing. 


\section{OBJETIVOS Y METODOLOGÍA}

En las últimas décadas y a raíz de las corrientes posestructuralistas, se ha incidido en el naufragio del signo de forma constitutiva, en su inherente incapacidad para apresar y trasladar la realidad de lo designado. En el clima de deconstrucción, la cualidad de lo inefable ha perdido exclusividad y, si antes se empleaba para ciertas circunstancias excepcionales, ahora puede verse como una etiqueta que engloba a la realidad por completo. Sin embargo, resulta obvio que en el campo de la designación hay una escala entre lo no-mentable y lo mentable, pese a que este último tampoco lo sea enteramente. Descripciones, por ejemplo, de más difícil expresión o literalización, y no por defecto de narrador sino por cualidad del objeto a describir. Si no queremos salirnos del marco posestructuralista, diremos que existen realidades que hacen especialmente patente el carácter meramente aproximativo del lenguaje, y lo harán en virtud de su naturaleza radical y prodigiosa.

Para la contemplación y estudio de esta periferia del lenguaje, se ha recurrido a unos textos que parecen idóneos por lo prístino de la experiencia y la virginidad del protagonista-narrador. Se trata de textos autógrafos sobre conversiones súbitas, entendidas como el cambio de postura religiosa a raíz de un encuentro puntual y concreto con la divinidad. Por decirlo de otro modo, testimonios de experiencias místicas en sujetos no místicos, es decir, autores que han avistado la divinidad en una sola ocasión y que, por lo tanto, no podrán recurrir al afinamiento de la designación de quienes han sufrido varias experiencias en este sentido. Tanto el objeto de la experiencia -el ente inabarcable que conocemos por Dios-, como las características del fenómeno -puntual, inexplicable-, así como la bisoñez del narrador y protagonista -acontecimiento acecido una sola vez- propician la idoneidad de los textos.

Se han escogido tres autores de la primera mitad del siglo XX que partían de posiciones ateas o agnósticas. El corpus se justifica en tres sentidos principalmente:

a) Contemporaneidad. Debido a la proximidad temporal de los testimonios respecto a nuestros días y a la semejanza del paradigma imperante, que lo es desde la revolución científica. De esta manera podemos presuponer en los autores las mismas reservas modernas que en un lector de hogaño. Se evitarán las posibles sospechas sobre la capacidad analítica de los protagonistas por la semejanza y competencia de sus recursos explicativos-científicos. Asimismo, ya en el siglo XX, se compartía nuestra escasa permeabilidad para lo extraordinario o milagroso.

b) Increencia. Se trata de autores que partían del ateísmo o del agnosticismo, de forma que se muestra claramente su incapacidad hermenéutica y vivencial para acoger una experiencia de este tipo, lo que redundará en el desbordamiento de la percepción y de las condiciones apriorísticas que obra el acontecimiento.

c) Competencia. Se han elegido tres figuras de demostrada solvencia intelectual para abjurar la sospecha de enajenación que tan fácilmente podría sobrevolar estos casos. Son:

i. El literato Paul Claudel, quien se convirtió en Nôtre Dame a los 18 años de edad. Alejado de cualquier creencia religiosa y firmemente asentado en el determinismo materialista que imperaba entonces, acudió a la catedral en busca del impulso estético que pudiera brindarle el ritual católico. De repente, sin ningún estímulo concreto que pudiera calificarse de detonador, siente la existencia de Dios de forma casi física y una convicción religiosa que mantuvo hasta su muerte.

ii. El periodista André Frossard, quien se convirtió en una capilla de la calle Ulm, en París, cuando contaba con 20 años. Hijo de un destacado político socialista, Frossard vivía indiferente a la religión. El 8 de julio de 1935 entra en la mencionada capilla en busca de un amigo. Al igual que Claudel, sin que mediara ningún estímulo concreto, siente la mirada de Dios y cambia para siempre sus creencias y forma de vida.

iii. El filósofo Manuel García Morente, quien abandonó el agnosticismo en el año 1937, a los 51 años, también en París. Se encontraba acogido en el piso de un amigo y atormentado por la situación de su familia que permanecía en España en plena contienda civil. Tras escuchar por la radio una partitura de Berlioz, es asaltado por una serie de imágenes cristológicas. Esa misma noche despierta y siente con viveza la presencia de Cristo en su habitación. Tres años después se ordenaría sacerdote.

La conversión súbita, objeto y detonante de la afasia, consiste en una puntual experiencia mística donde la divinidad transparenta su existencia al sujeto $y$, fruto de la cual, este cambia su vida de posiciones arreligiosas a una postura vital de acendrada religiosidad y, como consecuencia de ella, intentará vivir se- 
gún la voluntad divina en adelante -kenosis-. Se trata, desde luego, de un acontecimiento de características peculiares, extraordinarias, que asimismo desplegará un mapa fenomenológico muy particular. Para acotarlo, se puede recurrir a lo que Jean-Luc Marion (2008) llama "fenómeno saturado" (p. 339), a su estatus de acontecimiento puro en tanto que rebasa todas las categorías del pensamiento y aun así aparece. Desencadena una sobreabundancia de significación que no puede ser aprehendida por la razón, sino por medio de la intuición, al estar esta más liberada de las categorías conceptuales que son desarboladas por la magnitud de la experiencia. Además se demuestra puramente vivencial: la certeza que extraiga el individuo no se produce por medio del repaso de consecuencias y premisas de lo que acontece, sino que el sentido se aporta súbitamente en el contexto de la experiencia y difícilmente se podrá extrapolar a un proceso racional.

Todo lo anterior no debe llevar a considerar el acontecimiento como vaporoso, indefinido o vago, sino todo lo contrario; se produce una certeza tan firme y con un contenido noético tan discernible, que la razón se muestra insuficiente para su aprehensión. Así pues, la experiencia torna obsoleta la razón y no al contrario.

Habría que recordar, por último, la diferencia entre 'indecible' e 'inefable', según la establece Vladimir Jankélévitch (2005) en su libro La música y lo inefable (p. 118). Lo indecible sería aquello que directamente no se deja penetrar de ningún modo, que es absolutamente inalcanzable por cualquier vía y que, por lo tanto, nada se puede decir al respecto. Lo inefable, por contra, es aquello que no se puede acotar por ser infinito e ilimitado y que, por ende, no puede trasplantarse fielmente al lenguaje. Así, en nuestro caso hablaremos de "lo inefable" pues, aunque su magnitud infinita impide un correlato lingüístico, aunque no pueda ser apresado por el razonamiento, si se presenta, es intuitivamente comprensible y el fracaso del idioma es posterior. Es decir, el narrador no encuentra el obstáculo en su interior, donde el fenómeno se presenta claro y definido, sino que la traba aparece cuando este acontecimiento intenta ser puesto en palabras para presentarlo fielmente al lector hipotético. Así, se tratará la afasia según lo inefable de la teofanía. Se podría argumentar que Dios es asimismo lo indecible, dado que cualquier término o referencia adulteraría su esencia; sin embargo, especialmente en estos casos, pasa de lo indecible al campo de lo inefable en tanto que se aparece, que irrumpe en la trayectoria de la vida humana para donar sentido donatio-. Toma la divinidad la iniciativa -kairós- para que el hombre pueda atisbar un fragmento, más bien un actante, de su Ser, en este caso la existencia activa.

Aquí se hablará de afasia según su acepción etimo-

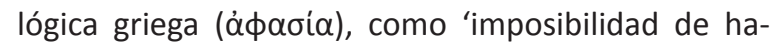
blar'. Esta incapacidad se plasma gráficamente y en varios niveles dentro de los textos autógrafos de conversión súbita. Si bien tamizadas por la personalidad y estilo de cada uno de los autores, las líneas maestras de los rasgos constitutivos se repetirán en todos ellos, fijando así un esquema fenomenológico y narratológico común.

\section{AFASIA SEGÚN LA DIVINIDAD}

[...] [S]ería ignorancia pensar que los dichos de amor en intelligencia mística, quales son los de las presentes canciones, con alguna manera de palabras que se puedan bien explicar, porque el spíritu del Señor [...] pide por nosotros con gemidos ynefables lo que nosotros no podemos bien entender ni comprehender para lo manifestar. Porque ¿quién podrá escribir lo que á las almas amorosas donde él mora haze entender? Y ¿Quién podrá manifestar con palabras lo que las haze sentir? (Martínez de Burgos, 1962, pp. 3-4).

Son palabras del abulense san Juan de la Cruz como pórtico a su Cántico espiritual. Advierte de la incapacidad inherente al lenguaje para referir el encuentro con la divinidad. "Sería ignorancia", dice, explicar adecuadamente el contenido de la experiencia, obrar la traslación simbólica que exige la comunicación humana. Se ha citado, no debe olvidarse, quizás al que más se ha acercado a expresar lo inexpresable, un finísimo escribiente con una larga experiencia en el campo místico. Más rotunda, por tanto, será la afasia que aqueje a nuestros protagonistas, cuyos encuentros con la divinidad solo se produjeron en una ocasión y, por lo tanto, carecen de esa "abundante intelligencia mística" (Martínez de Burgos, 1962, p. 5) que el de Fontiveros sí poseía. Los presentes autores estarán privados de la intimidad con el acontecimiento que tendrán otros místicos de largo recorrido, ya que sus encuentros han sido únicos y fortuitos, no destino de un largo proceso ascético de vaciamiento y perfección para alcanzar la gracia mística. A propósito, André Frossard insiste en que su libro es el "atestado de un accidente", pues narra cómo no iba hacia al catolicismo cuando con él se topó $(1969$, p. 8).

Al margen de la sapiencia en descripciones místicas de cada autor, la imposibilidad de hablar es constitutivamente anterior y provendrá del objeto. Es Dios materia inefable por antonomasia, lo que el filósofo 
austriaco Ludwig Wittgenstein (2010) denominaba "lo místico", es decir, el lenguaje refiriéndose a lo indesignable, a lo que, a todas luces, excede su naturaleza y por tanto defrauda su función (pp. 131-132) -el filósofo austriaco no hace la distinción entre indecible e inefable que sí vimos en Jankélévitch (2005, p. 118)-. La teofanía supone un "fenómeno saturado" que da un exceso de intuición al margen de cualquier prescripción conceptual. Por lo tanto, si se produce una ruina del concepto, ¿cómo acudir a una convención como es la idiomática? Se difumina, o más bien no se deja apresar, la primera condición de la comunicación lingüística: un ente delimitable. Y no se resiste a tenor de su abstracción, pues se concreta en la experiencia, sino por su naturaleza inabarcable para cualquier código. No puede llevarse a cabo, por tanto, la reificación que exige el lenguaje. Comenta Martin Buber al respecto:

Por su naturaleza, el Tú eterno no puede convertirse en Ello, pues por su naturaleza no puede ser reducido a medida sin límite, ni aun a la medida de lo inconmensurable ni al límite del ser ilimitado; porque, por su naturaleza, no puede ser pensado como una suma de propiedades, tampoco como una suma infinita de propiedades elevadas a la trascendencia; porque no puede ser encontrado ni en el mundo ni fuera del mundo; porque no puede ser empíricamente dado; porque no puede ser pensado (Buber, 2005, p. 98).

Dios es lo netamente indesignable. No podemos realizar un aislamiento de características en pos de una definición, no puede haber un aislamiento conceptual, siendo su esencia holística, inabarcable; nada en particular es Él, al tiempo que nada se le queda fuera. En la tradición monoteísta en que se inscriben nuestros testimonios, Dios, así con mayúsculas, es único a la vez que incognoscible, al menos desde el plano terrenal; por ende, si solo hay uno y nadie lo ha visto, cómo designarlo, cómo secuestrar su esencia. Se trata de la incapacidad de constituir un Ello, como decía Buber más arriba.

Ante el contacto, aunque mitigado -un desvelamiento total de Dios aniquilaría-, con esta entidad que debe situarse en la cima del Ser, el sujeto siente la sensación punzante de ser testigo indigno debido al desfase ontológico entre la criatura y el Creador. "Ô Infini, il n'y a rien d'assez étroit dans mon cœur pour Te contenir!" (Claudel, citado en Chrétien, 2007, p. 240). He aquí la tragedia íntima de cualquier experiencia mística: el hombre se muestra receptáculo insuficiente. Es tanta la grandeza y la gracia que se derrama, que apenas puede hacerse el individuo eco de ello; de ahí una de las vertientes que cobra el componente de inefabilidad. El contacto con la entidad ontológica mayor por definición-Dios-, más aún cuando es repentino, a modo de choque, produce un sobrecogimiento por el contraste entre dos naturalezas tan distantes: la divina y la humana.

Para introducirse en ese estado, el hombre no puede permanecer en su condición ordinaria, ya que, de ordinario Dios no se manifiesta de esa manera. Habrá de recordarse que se trata de una experiencia única que por sí sola se basta para cambiar toda una vida. Para penetrar en esta revelación, en esta experiencia en sí saturada, se precisa que el sujeto sobrepase sus propios límites, excediendo su naturaleza y su inmanencia; también su capacidad sensorial que se muestra aquí deficitaria cuanto menos. Es lo que Jean-Louis Chrétien llama dilatation (2007, p. 246) y que exige un proceso de amplificación, incluso de salida de sí -éxtasis' significa salida-. El sujeto ha de adaptarse para una revelación que rebasa una a una sus categorías, incluida, desde luego, la conceptual y de ahí la lingüística. Lo que implica también una epojé en el sentido fenomenológico -diferente, por ejemplo, a la ataraxia budista-, un poner en paréntesis la experiencia que se legitima en sí, al margen del curso preestablecido de la realidad que la experiencia del mundo habrá trazado. En otras palabras, la teofanía ha de ser considerada insularmente, deponiendo las expectativas del sujeto. En sí misma se muestra perfectamente comprensible y armónica, el problema sobreviene cuando ha de compararse con el resto de experiencias y echar mano del lenguaje que, ahora definitivamente, se revela como instrumento insuficiente. Necesitará, por tanto, un lenguaje nuevo, nacido de las exigencias de la hierofanía, completamente desemejante al consensuado que el hombre emplea en su comunicación cotidiana. De alguna forma el lenguaje debería salirse de sus vías, desencajarse de igual manera que lo había hecho el sujeto y su concepción del mundo.

Todos estos elementos, necesariamente, apuntan a un fenómeno y un ente inabarcable, de una magnitud inescrutable. No obstante, si se recurre a los testimonios de conversión súbita, se comprueba que no es la grandeza la impresión refleja que el sujeto recibe de la divinidad. Por ejemplo, el citado Paul Claudel describe: "J'avais eu tout à coup le sentiment déchirant de l'innocence, de l'éternelle enfance de Dieu, une révélation ineffable" (1965, p. 1010). Por su parte, el filósofo español Manuel García Morente sufrirá la teofanía durante la audición de La infancia de Jesús de Berlioz y tras presentársele los primeros compases de la vida de Cristo (García Morente, 2002, pp. 36-38). En 
contra de lo que cabría esperar, la primera impresión de los testigos se refiere a la inocencia, la ternura, la infancia o la pureza; lo que resulta sorprendente a tenor de la magnitud insondable de quien se manifiesta. Así pues, cabe identificar la vía sensitiva e intuitiva como primordial en esta experiencia, ya que, probablemente, un proceso racional hubiera destacado en primer lugar la grandiosidad, que pasa por ser el rasgo más directamente aplicable al ente divino.

Lo anterior incide en algo que ya se ha anotado: se trata de una experiencia vivida de forma adánica, ya que el sujeto no puede recurrir a categorías previas. No serán pues experiencias de tipo teológico -considerando la teología como ciencia racional-, sino puro encuentro vivencial, personal con la entidad que la ciencia religiosa, si se quiere, solo conoce indirectamente. Son oportunas las palabras de Job en 42, 5: "Antes te conocía de oídas, ahora te han visto mis ojos". Se trata justamente de la diferencia entre conocer algo por especulación racional y hacerlo por medio del encuentro, de la experiencia.

Otra de las cualidades constitutivas del objeto divino, siempre según la experiencia de los protagonistas, está en plena consonancia con la propia etimología del término, pues Dios proviene de la raíz indoeuropea deiw- 'brillar, ser blanco'. "Yo soy la luz del mundo", leemos en Jn. 8, 12. Pero es una luz insospechada e incomparable, por eso produce un innombrable deleite, aunque también estupor. La reacción humana ante esta característica divina es descrita por André Frossard (1969) con una gráfica comparación: “J'étais une chouette en plein midi, qui fait l'expérience du soleil" (p. 169). Afirma poco después en el mismo capítulo: "lumière qui faisait pâlir le jour" (p. 171), lo que hace inevitable la mención a La noche oscura de san Juan de la Cruz donde pondera: "más cierto que la luz del mediodía" (1992, p. 261) o a Jb. 11, 17: "Tu vida será más radiante que el mediodía". Es pues el grado máximo de luz que sería insoportable para el hombre si esta no fuera acompañada de "dulzura" en el mismo grado. Esta iluminación, además, se utiliza en sentido figurado en tanto que conlleva la aportación de sentido a la vida, es decir, el esclarecimiento gracias a la luminaria de la nueva verdad descubierta. Y lo hace sin verbalidad, sin figuración; es una comunicación previa o superior al lenguaje, no hay mediación significativa: "révélé et masqué par cette délégation de lumière qui sans discours ni figures donnait tout à comprendre et tout à aimer" (Frossard, 1969, p. 162). Y esto granjea al sujeto lo que el teólogo Lluís Duch llama "pensamiento sacramental" (1979, p. 46), a te- nor del cual el hombre ve al unísono lo inmanente y lo trascendente, estando lo primero en la matriz de lo segundo; es lo que se denomina una visión del mundo sub specie divinitatis.

En todo este exceso se produce un anonadamiento maravilloso del sujeto. He ahí el reflejo más fisiológico de la afasia en estos casos, la imposibilidad de hablar en el sentido más obvio. La teofanía desencadena una experiencia de tanta intensidad, que el sujeto enmudece incapaz de articular palabra en el contexto del encuentro. Queda, literalmente, boquiabierto. De ahí que no se pueda hablar de diálogo, pues el sujeto no puede responder a Dios, no se constituye como interlocutor. Es preciso anotar que el acontecimiento es, en terminología de Juan Martín Velasco (1995), "teopático" (p. 47): el hombre padece la experiencia, no es componente activo del proceso, sino pasivo. En primer lugar porque la iniciativa corresponde al ente divino, por medio de la Gracia -kairós- y, en segundo lugar, porque al hombre le está vedada la contemplación plena de la divinidad, la cual resulta ontológicamente inobservable. Lo que sucede, pues, es que el sujeto siente la mirada de Dios sobre él, siente que se le transparenta momentáneamente la existencia de Dios, pero no porque lo vea, sino porque siente su mirada. En tal caso, el sujeto queda paralizado, con la palabra arrebatada y constituido como objeto, de ahí que se le pueda denominar como sujeto paciente en tanto que recibe la acción. Cierto que, según el presupuesto teológico, Dios nos observa constantemente; lo que cambia es la conciencia palpable y puntual de este hecho en el objeto, en el sujeto paciente. Se produce una grieta momentánea en la ocultación divina y su sempiterna vigilancia es percibida nítidamente por quien es observado.

La cohesión o el eje armonizador de todos estos elementos, de tan difícil distinción y catalogación, será la Presencia, el estar ahí de la divinidad que se manifiesta. Será esta presencia el origen y sustancia de toda la experiencia y por ende de la narración. Presencia que, al demostrarse activa, se revela amorosa en su iniciativa de comunicación, ya que su interlocución con el hombre, ontológicamente menor, implica un abajamiento, un descendimiento. Siendo su naturaleza, por definición, autosuficiente, la intervención a favor del sujeto pasivo no puede explicarse sino como un acto de amor. Asimismo, la comprobación de que Dios existe y reivindica lo humano al revelársele, es ya una certeza de redención. Dios se confirma personal. De ahí que el hombre refiera en multitud de ocasiones la relación divina en clave amorosa; como 
así demuestra la producción de san Juan de la Cruz y toda la dialéctica del deseo formada alrededor de la unio mystica (Haas, 2009, p. 89). Frossard (1969) sigue esta línea y acaba su libro con una declaración digna de cualquier epístola romántica, casi un piropo; eso sí, como correspondencia a un amor excesivo y eterno en tanto que divino: "Amour, pour te dire, l'éternité sera courte" (p. 167).

\section{AFASIA POR LAS CARACTERÍSTICAS DE LA EXPERIENCIA}

Otra de las imposibilidades para la expresión de la teofanía es relativa a la imposibilidad de síntesis, al menos de la síntesis sucesiva, lo que imposibilita una narración ordenada o casuística. Lo que el narradorprotagonista suele relatar son las sensaciones y consecuencias derivadas de la experiencia, pero no la experiencia en sí. Esta no se puede descomponer o resultar como la suma de sus partes; es una unidad experiencial indivisible, al tiempo que inconmensurable. Por consiguiente, no cabría la recopilación de características en pos de la definición:

Además, esa desmesura no se ejerce siempre ni de entrada a partir de la enormidad de una cantidad sin delimitaciones; esa desmesura se caracteriza más a menudo por nuestra simple imposibilidad de aplicar una síntesis sucesiva que permita prever un agregado a partir de la suma finita de sus partes finitas. Como el fenómeno saturado sobrepasa la suma de sus partes -las cuales tampoco pueden a menudo enumerarse-, hay que abandonar la síntesis sucesiva por lo que llamaremos una síntesis instantánea, cuya representación precede y sobrepasa la de los eventuales componentes, en lugar de resultar según la previsión (Marion, 2008, p. 331).

Explica su caso García Morente y resbala. Por una parte, asegura la presencia que marca el acontecimiento, por otra, sin embargo, no sabe precisar ni cómo ni cuándo esto sucedió, simplemente lo hizo. No puede seguir un discurso del tipo "vi esto, con esta forma, y eso me hizo pensar aquello":

¿Cómo es esto posible? Yo no lo sé. Pero sé que él estaba allí presente y que yo, sin ver, ni oír, ni oler, ni gustar, ni tocar nada, le percibía con absoluta e indubitable evidencia (García Morente, 2002, pp. 42-43).

La manifestación de lo divino no puede ser expresada con palabras. Por coherencia ontológica, la comunicación de la divinidad es pre-lingüística, tiene que ver más con la palabra primordial -“En el principio existía la Palabra" (Jn. 1, 1), esencial -urdimbre de cualquier lenguaje posterior- ${ }^{-1} \mathrm{y}$, por tanto, anterior a cualquier comunicación consensuada de ámbito puramente humano. Así pues, la traducción de significado a significante es imposible o, al menos, fraudulenta. En la conversión súbita la divinidad no traslada palabras, no hay un discurso en sentido lingüístico; más bien se habla de "sensación", "impresión", "sentimiento". Estos términos no se refieren a una experiencia subjetivista o peyorativamente emocional, sino que se centran, una vez más con insuficiencia, en una experiencia que no es susceptible de ser reducida a conceptos o vocablos de ordenación racional. Así, la teofanía no es una experiencia sub-racional, sino supra-racional. Esto no quita, por otra parte, que haya un mensaje presente y perfectamente comprensible, aunque sea la sola confirmación de la existencia de Dios y de su naturaleza amorosa.

Dice Claudel:

En essayant, comme je l'ai fait souvent, de reconstituer les minutes qui suivirent cet instant extraordinaire, je retrouve les éléments suivants qui, cependant, ne formaient qu'un seul éclair [...] (Claudel, 1965, p. 1010).

La comunicación de la teofanía al resto -al fin y al cabo ese es el intento de cualquier escrito de conversión- es ardua. No solo por la naturaleza de la divinidad, sino por la fisionomía de la experiencia que disfruta el sujeto: única, súbita y difícilmente medible. Al recurrir Claudel a la imagen de éclair, además de una posible relación con la imagen del fuego como fuerza unitiva y asimiladora (Haas, 2009, p. 88), dibuja gráficamente lo que supuso y la dificultad inherente a su comunicación. El protagonista-narrador debe tomar un suceso que acaeció múltiple y complejo en simultaneidad, al tiempo que unívoco, diseccionarlo y presentarlo, diferenciando posibles causas, características y conclusiones. Obviamente supone una desnaturalización: primero, se trata de un suceso que no resulta de la unión de sus partes, por lo que cualquier recorrido por sus cualidades o reflejos nunca brindará una imagen completa y fidedigna, esto es, no existe sustitución textual legítima; segundo, porque la experiencia vendrá mediada por el tamiz del receptor, esto es, no se puede saber cómo se manifiesta lo divino sino cómo Claudel lo percibe, con sus subsiguientes interpretaciones o personalismos.

Igualmente la experiencia conserva el marchamo de su generador, siendo, por tanto, resistente a cualquier cómputo temporal definido. García Morente, por ejemplo, se resiste a establecer una horquilla temporal concreta, ya que, en el sucederse de la teofanía, se anulan o trascienden los cómputos; lo que vendrá a 
redundar en su dificultad para ser narrada: “¿Cuánto tiempo duró su presencia? Ya he dicho que no lo sé" (García Morente, 2002, p. 43).

\section{AFASIA POR LO SUBJETIVO}

Recurriremos ahora a los números 283-325 de las Investigaciones filosóficas de Ludwig Wittgenstein (2004, pp. 91-99). Del pensador austríaco, más concretamente de su segunda etapa donde depone levemente su escepticismo en la posibilidad de comunicación lingüística, nos interesa lo relativo a lo subjetivo del lenguaje privado: cómo, a raíz de la experiencia privada, se constituye un uso público, consensuado. Cualquier experiencia, al verbalizarse, pasa del comportamiento no-hablado al hablado, por medio de unos juegos de adaptación lingüística que van asemejando el sentimiento de uno con el de otro. Se pasa, del ámbito privado de la experiencia, a una conceptualización común que permite agrupar varias experiencias subjetivas bajo un común significante objetivo. Sin embargo, ¿se puede hablar de juegos lingüísticos en la teofanía? Probablemente no por dos razones fundamentalmente: a) es imposible destacar las características principales que facilitarían la sustitución lingüística; b) no puede dejar de ser una experiencia enteramente privada en tanto que vivencial y puntual, por lo que ningún relato podrá activar la experiencia en el otro.

Las cualidades que se han ido adjudicando al fenómeno de la teofanía-vivencial, saturado, intuitivo, etcétera-, hacen que sea esencialmente incomunicable; sobre todo en dos aspectos: el carácter experiencialpersonal y la inefabilidad de lo revelado. Por lo tanto, dado que solo el que lo experimenta puede comprenderlo, cualquier comunicación será siempre deficitaria. Si normalmente se ha dicho que cualquier tipo de significante lingüístico es una mera aproximación convencional a la realidad, en este caso es especialmente tangible. $Y$ es que, si a Dios solo se le puede conocer en el encuentro, el significante, para el que no haya "sufrido" la experiencia, está más que nunca desligado de su referente.

Si es personal e intransferible, si solo quien lo experimenta lo conoce, si la dislocación del tiempo impide acometer la narración, ¿̇por qué intentar comunicarlo? Por la pertinencia de las implicaciones. Aunque Dios se le transparente en un momento dado a un sujeto $x$ y solo a él, que lo haga tiene pertinencia universal, pues es Dios uno y de todos. Por consiguiente, pese a la insuficiencia palmaria del testimonio, los conversos sienten la obligación de comunicar su expe- riencia, en la mayoría de los casos, dada la importancia de la verdad de que han sido depositarios.

\section{AFASIA EN LA METÁFORA}

En un punto de su testimonio, André Frossard (1969, p. 166) confiesa su miedo a caer en "quimera" a la hora de describir el fenómeno. Aun presuponiendo la validez del símbolo para referir la realidad, cuál podría utilizarse para describir lo inefable por antonomasia. Las palabras adulterarán, por tanto, la experiencia de la teofanía y, por ende, la harán de algún modo intransferible, habiendo sido, la certeza implantada directamente en el alma del sujeto paciente, sin traducción humana; solo su efecto en el sujeto pasivo puede ser comprensible para un tercero. Se trata de lo que no puede ser referido e infringe una frustración connatural a este tipo de escritos. No obstante, esta consideración no debe extenderse más allá, ya que el acontecimiento es inefable, intransferible, pero no ininteligible. Para el sujeto paciente, contuvo una significación clara, incluso con una elocuencia mayor de la que puede ser encontrada en nuestra comunicación cotidiana. Lo dibuja con precisión y belleza, de nuevo, san Juan de la Cruz (1992, p. 264):
Entréme donde no supe
y quedéme no sabiendo
[...] y el espíritu dotado
de un entender no entendiendo
toda sciencia trascendiendo.

Esta expresión paradójica, plena de oxímoron, refleja vivamente las características de la experiencia. Se trata de un saber diáfano otorgado por la intuición mística que se brinda, pero, al mismo tiempo, su taxonomía es tan desemejante a nuestro conocimiento ordinario y al orden de nuestra experiencia común, que la comunicación deviene imposible, quimera. Situación de radical novedad para el sujeto paciente, quien carece de las categorías mentales para diseccionar y de los recursos lingüísticos para apresar, sin que esto impida que el conocer se produzca y lo haga en un nivel de certidumbre incomparable. Se ve, pues, que la dicotomía ignorancia-conocimiento se aúna en un mismo suceso: mientras se desconoce, o más bien no se puede esquematizar, la taxonomía de la experiencia por provenir del incognoscible divino -Mysterium tremendum-, se incuba en el hombre un conocimiento súbito sobre el origen y finalidad del mundo a tenor de su derivación del Ser Supremo. Se desconoce el porqué y el cómo de la experiencia que da sentido a toda la realidad; he ahí la paradoja. 
En consonancia con lo anterior, a la hora de describir lo sucedido, se encuentran una serie de calificativos o ideas que pueden resultar antitéticas, haciendo uso de la coincidentia oppositorum. Se trata de un recurso literario que, aunque utilizado por la tradición mística, también es rastreable, por ejemplo, en buena parte del Siglo de Oro español, sobre todo con relación a temas amorosos. Se contraponen dos elementos opuestos, y del choque surge un tercero que no es abordable directamente, que solo puede ser sugerido rompiendo la lógica designativa. Es más, cuando se trata del inefable místico, de la experiencia totalmente otra, múltiple y unívoca, no pueden más que contradecirse o quebrarse las reglas de lo decible. En el caso de la teofanía, el recurso cobra un doble sentido: a) como palmeo lingüístico y balbuceo conceptual para intentar expresar lo inefable; b) como acercamiento a la descripción, siendo la divinidad el Todo, sin que nada se le quede fuera, de forma que es imposible, como tantas veces se ha visto, referirse a Dios en términos que no sean negativos u holísticos -inmortal, imperecedero, inefable, inescrutable, omnisciente, omnipotente-. Por otra parte, como señala Martín Velasco (1995, pp. 55-56), también se emplea la armonía de contrastes para referirse al efecto o sentimientos que el encuentro origina en el hombre. Produce en el sujeto paciente una "ambivalencia afectiva" debido a la doble vertiente de lo manifestado:

- Debida a un Dios trascendente, excelencia suma, cima ontológica, Creador absoluto.

- Debida a un Dios inmanente, que colma amorosamente el más íntimo deseo humano.

El teólogo Olegario González de Cardedal ha señalado las exigencias metaforizantes cuando de hablar de la experiencia de Dios se trata (1996, pp. 4-6). En cada caso particular se comprobará la insuficiencia de las técnicas tropológicas; pese a ello, la metáfora pasa por ser el único recurso posible para comunicar algo que el emisor no puede acotar y que el receptor no alcanza a imaginar. No se puede construir una imagen de sustitución, la cual, por medio de elementos conocidos, dé a entender lo desconocido; lo que, en última instancia, supone también el fracaso de la metáfora. Por tanto, aunque esta aparezca como único instrumento posible, lo será de forma insuficiente y nos hará hablar de una catecresis: "en falta de un verbum propium, permite el uso [...] de una imagen debilitada como denominación para ese objeto" (Haas, 2009, p. 25). Esto implica un empleo fraudulento o insuficiente del tropo, pues su naturaleza precaria, aun infinitamente distante a la realidad que designa, sirve más para apuntar que para comunicar su esencia; es, por así decirlo, un deíctico más que un concepto. No hay base objetual con que constituir significante, sino necesidad vivencial, implicante:

De la otra ladera sólo podemos hablar desde la atención, la audición y el anhelo; y con palabras de este mundo que remiten a realidades, experiencias y esperanzas de este mundo. Toda palabra sobre ella es metáfora ( forma posible para decir desde lo nuestro conocido lo otro desconocido; y única forma para que esa otra ladera, yendo más allá de sí, llegue hasta nosotros sin alterarse o reducirse. Ir más allá de sí exige salir de sí, tanto a la realidad cognoscible como al sujeto cognoscente. La metáfora nombra la forma en que la realidad se trasciende a sí misma hasta el sujeto cognoscente y

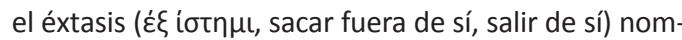
bra la forma en que el sujeto cognoscente es atraído hasta la realidad, connaturalizándose con ella y no sometiéndosela (González de Cardedal, 1996, pp. 5-6).

Dice al respecto Frossard (1969): “Le peintre à qui il serait donné d'entrevoir des couleurs inconnues, avec quoi les peindrait-il?" (p. 166). La imagen es certera para ejemplificar la problemática de la representación. No hay asidero comparativo posible ni estructuras analógicas para una aproximación satisfactoria. No caben aquí descripciones a base de un conjunto de realidades conocidas para que el lector se haga la idea de una realidad desconocida. Cualquier descripción por acumulación es insuficiente. Lo Absoluto se encuentra en un nivel inaccesible para el hombre, y si se entrevé -entrevoir-, la experiencia es incomunicable según un esquema terrestre. La divinidad, según la experiencia de los protagonistas, es incomparable con todo lo conocido, incluso con todo lo desconocido.

Ninguna de los cuatro pilares tropológicos que señala Haas (2009, pp. 30-31) sirven en este caso: ni la metáfora que parte de la similitud en la diferencia, ni la metonimia que reduce el todo a la parte-recordemos que Dios no es reductible a una de sus partes, pues es un Todo no parcelable-, ni la sinécdoque por la misma razón, ni siquiera la ironía. En este sentido, García Morente (2002) intenta expresar una sensación concreta concatenando comparaciones para, al final del fragmento, certificar la insuficiencia de la comparación al emplear imágenes sensitivas para algo que no fue tal:

Era como una suspensión de todo lo que en el cuerpo pesa y gravita, una sutileza tan delicada de toda mi materia, que dijérase no tenía corporeidad, como si yo todo hubiese sido transformado en un suspiro 
o céfiro o hálito. Era una caricia infinitamente suave, impalpable, incorpórea, que emanaba de Él y que me envolvía y me sustentaba en vilo, como la madre que tiene en sus brazos al niño. Pero sin ninguna sensación concreta de tacto (p. 43).

El mismo García Morente, tras un pormenorizado estudio analítico de su experiencia, tras sopesarla filosóficamente e intentar fijar sus atribuciones y particularidades, no tiene más remedio que darse por vencido y exclamar: “iJesús, Jesús! ¡Bondad! ¡Misericordia! Una figura blanca, una sonrisa, un ademán de amor, de perdón, de universal ternura. ¡Jesús!" (2002, p. 42). Se asiste a la enumeración de diversos calificativos o cualidades, un recorrido apresurado por las características del ente manifestado que, no obstante, no resulta de la suma de sus propiedades. Por eso, el autor va acumulando apelativos o representaciones hasta que vuelve a la única palabra que le hace justicia y, como dando en el centro de la diana, recurre al nombre propio que nos sitúa en el marco de un encuentro personal; de nuevo, vivencial, que no constituye objeto, sino que es el Ser mismo, en sí, en comunicación. Asimismo, el nombre propio y el encuentro por tanto personal, nos aleja de la vaguedad que a veces se percibe en las designaciones místicas. No se trata de un "je ne sais quoi", pues el origen y contenido están perfectamente delimitados: la transparencia puntual que confirma que Jesús de Nazaret es Dios mismo. Donde sí cabe la expresión francesa es en la explicación y narración de las particularidades de la experiencia y de la naturaleza de la intuición que brinda. Así, lo que se intuye está claro, lo que resulta confuso es el modo en que se intuye.

\section{AFASIA Y ESTILO}

Según se ha ido viendo, la aplicación lógica o adecuada del lenguaje, en cuanto rebasado, sería desarticulada, impresionista, vaga quizás en su intento de aprehender lo inaprehensible. El ejemplo paradigmático se encuentra en Blaise Pascal y la nota autógrafa que, relativa a su conversión, encontraron tejida en una de sus prendas tras su muerte:

Desde aproximadamente las diez y media de la noche, hasta aproximadamente las doce y media.

Fuego.

"Dios de Abraham, Dios de Isaac, Dios de Jacob" y no de filósofos y sabios. Certeza. Certeza.

Sentimiento. Alegría. Paz.

Dios de Jesucristo. [...]
Alegría, alegría, Ilantos de alegría.

Yo me he alejado.

Derelinquerunt me fontem aquae vivae

"Dios mío, ¿̇seré yo abandonado?"

Que yo no esté nunca separado de Él por toda la eternidad.

"Esta es la vida eterna, que te conozcan a Ti solo Dios

verdadero, y a aquel a quién has enviado, Jesucristo"

Jesucristo. Jesucristo (citado en Jürgen Baden, 1969, pp. 48-49).

Periodos cortos, repeticiones, escasez de verbos, asociaciones, evocaciones insinuadas, estructura caótica... todo lo anterior concuerda con la temática y las circunstancias de la experiencia. Ahora bien, sería injusto desacreditar los testimonios de conversión que no presenten estos rasgos, porque, si bien lo narrado es lo mismo, la naturaleza del texto difiere. El documento de Pascal era de ámbito personal - nadie más lo leyó en vida-, por lo que bastaba una serie de asociaciones que le recordaran el acontecimiento de aquella noche. Por el contrario, Claudel, Frossard y García Morente -este último en una epístola privada pero destinada a explicar el fenómeno a un tercero- procuraron con su texto representar lo más claramente posible el suceso que desencadenó su conversión, de forma que fuera comprensible para un lector hipotético. Aun así, se pueden encontrar restos de esta justicia lingüística cuando intentan rescatar sus pensamientos en el momento preciso. Los tres recurren al lenguaje fragmentado, de periodos cortos y básicamente centrado en los deícticos -primer estadio del lenguaje-. Será suficiente un ejemplo en cada caso:

Claudel: "C'est vrai ! Dieu existe, II est là. C'est quelqu'un, c'est un être aussi personnel que moi ! ॥ m'aime, Il m'appelle" (1965, p. 1010).

Frossard: "Il est la réalité, il est la vérité" (1969, p. 158).

Morente: "Volví la cara hacia el interior de la habitación y me quedé petrificado. Allí estaba Él" (2002, p. 42).

El ánimo divulgativo general, que sí poseen los escritos de Claudel y Frossard, aconsejaría una estructura sencilla y un estilo diáfano. En el caso de Claudel la contención es patente, más aún considerando el estilo florido de su producción literaria. El poeta francés embrida su estilo, decantándose por periodos cortos, adjetivación moderada y sencillez tropológica. Impide cualquier ejercicio retórico patente que pueda parecer como deliberada intención del autor de producir un efecto. Se palia la voz del autor a favor de la narración aséptica de los acontecimientos. Quiere, 
en definitiva, ser cronista fidedigno, neutral. Se podría hablar de una redacción casi telegráfica y un respeto por el orden no marcado de las oraciones. Si acaso, se aprecia cierto extrañamiento cuando se relata el momento ontológico -teofanía-. Sin embargo, se trata más bien de un intento de simplificación comunicativa de lo inefable que, por más que se pretenda claridad, no puede ser expresado de forma convencional, pues la misma naturaleza del hecho lo impide, lo que acabará desembocando, aunque solo como intento, en algunas contorsiones de la expresión. Sería oportuno el propósito de Michel Leiris para su Edad de hombre, que dejó manifestado en De la literatura considerada como una tauromaquia:

Porque decir la verdad y nada más que la verdad no lo es todo: falta todavía abordarla directamente y decirla sin los artificios de las grandes arias destinadas a imponerse mediante trémolos y sollozos en la voz

[...] decir todo y decirlo desdeñando todo énfasis, sin abandonar nada a la facilidad, como obedeciendo a una necesidad [...] (Leiris, 2005, p. 20).

El cometido que Claudel perseguía con la concreción y desnudez estilística era dotar de credibilidad al escrito, huyendo de la desconfianza o lejanía que el ornamento o la exageración de una prosa colorista pudieran suponer. Un estilo marcado puede antojarse como revisión y añadidura al tema en sí, lo que suma una distancia entre el lector y el contenido del texto. La finalidad es evitar la sensación de reelaboración que mediatizaría el proceso, disimular lo suficiente la pluma del escribiente para otorgar un cariz científico, de crónica aséptica.

Cuando la intención testimonial se impone sobre los demás componentes de la autobiografía, la enunciación tiende a la homogeneidad, a la mimetización de la realización oral y al estilo transparente (el noestilo), con lo que se difuminan los límites entre autor y lector reales y sus representantes textuales, y la credibilidad y veracidad del discurso se acentúa (Fernández Prieto, 2004, p. 425).

Igualmente, este modo que exige la neutralidad dificulta aún más la narración de la teofanía. Por coherencia literaria, sería la poesía el género que más se aproximaría a las características de la experiencia por su naturaleza sugerente, evocadora y más libre a la hora de emplear y engarzar conceptos. Sin embargo, el empleo de ese género contradiría el espíritu de objetividad, ya que la lírica, más que ninguna otra forma de escritura, interpone más patentemente el prisma de lo subjetivo frente a la realidad. Así pues, el cometido de crónica o testimonio que buscan los autores desaconseja al mismo tiempo el uso del modus loquendi más apropiado para expresar la experiencia de la teofanía.

De cualquier forma, no se debe olvidar que el núcleo temático y narrativo debe ser el momento ontológico, ese in preaesentia Dei stare (Haas, 2009, p. 64) que supone un acto sacramental. Los títulos de los textos son bastante explícitos al respecto: Ma conversion; Dieu existe je L'ai recontré; El Hecho Extraordinario, este último titulado por el editor a posteriori al tratarse de una epístola privada publicada a la muerte del autor. Así, se trata de testimonios de conversión y, siendo esta súbita, el clímax y asunto de los escritos debe ser la teofanía, el encuentro puntual con la divinidad. Cuando se acomete la narración del momento ontológico, se suceden una serie de giros lingüísticos ya apuntados: la afasia, la emotividad del lenguaje, el discurso fragmentario, las imágenes de sustitución, metáforas, etcétera. El lenguaje se ve obligado a sobrepasarse a sí mismo para seguir siendo referencial y comunicativo, pues se pretende que un interlocutor se haga la idea más aproximada posible sobre algo que en esencia es incomunicable. Se da por tanto la paradoja de que el hecho fundamental de la narración recibe poco desarrollo, en lo que a espacio se refiere, dada su naturaleza extraordinaria e inefable. Lo que podemos ver, y nuestros autores insisten en ello, son las consecuencias en la vida del sujeto pasivo; pero apenas nos es trasmitido el momento de dilatación poética e íntima que compone el momento ontológico. De ahí que el mayor tratamiento narrativo lo reciban los momentos colindantes, tanto anteriores como posteriores, pues, en puridad, ante la epifanía solo vale callar.

\section{CONCLUSIONES}

A lo largo de estas páginas se han establecido los distintos niveles en que irrumpe la afasia en los textos autógrafos de conversión súbita. El primer nivel y más obvio corresponderá al objeto que hay que describir: Dios, el ente inefable por antonomasia en virtud de su naturaleza inabarcable. Así pues, una experiencia consistente en el avistamiento de la divinidad será paradigmáticamente indesignable y producirá un estupor afásico en el testigo. De ahí se pasa a un segundo nivel que corresponderá a las características de la experiencia. Se ha dicho que se trata de un fenómeno saturado, de un acontecimiento puro que excede las categorías racionales y que, si bien dona sentido, lo hace por medio de la intuición mística y, por lo tanto, con un carácter 
no-mentable. En tercer lugar, el componente subjetivo que colabora decisivamente en la incomunicabilidad del fenómeno. Por último, centrándonos en el lenguaje, se ve que igualmente se muestran insuficientes sus métodos -analogías, metáforas- para expresar lo desconocido o lo inalcanzable. No existe asidero comparativo ni recurso tropológico viable que pueda dibujar la realidad en un lector hipotético. En definitiva, una afasia crónica que invade cada uno de los niveles, tanto de la experiencia como del texto que intenta describirla.

Se ha constatado la frustración irrefragable que surge cuando se intenta poner por escrito algo que excede ostensiblemente la sustancia lingüística. Frustración empero que debe ser asumida por estos narradores debido a la necesidad de comunicación que conlleva la pertinencia universal del acontecimiento. Así, como se señalaba al principio, los testimonios de conversión súbita suponen el idóneo espécimen para el estudio y contemplación de la afasia en todos los niveles -autoral, textual y referencial-. Debido, entre otras cosas, al interés testimonial y neutro de los textos, se aprecia aquí la ejemplificación más radical de esa exasperación designativa que aflora al intentar acotar lo que es ilimitado.

\section{NOTAS}

1. "Los antiguos habían distinguido con toda precisión el logos endiathetos o verbo interno del logos prophoricos o verbo externo. La palabra va siempre con nosotros aunque callemos o sobre todo cuando callamos. Porque la palabra no destinada al consumo instrumental es la que nos constituye: la palabra que no hablamos, la que habla en nosotros y nosotros, a veces, trasladamos en el decir" (Valente, 2000, p. 62).

\section{BIBLIOGRAFÍA}

Buber, M. (2005). Yo y Tú. Madrid: Caparrós editores.

Chrétien, J.-L. (2007). La joie spacieuse. París: Les Éditions de Minuit.

Claudel, P. (1965). Oeuvres complètes. París: Gallimard.

Duch, L. (1979). La experiencia religiosa en el contexto de la cultura contemporánea. Barcelona: Bruño.

Fernández Prieto, C. (2004). Enunciación y comunicación en la autobiografía. En Fernández Prieto, C. y Hermosilla Álvarez, M. A. (eds). Autobiografía en España: un balance. Madrid: Visor, pp. 417-432.

Frossard, A. (1969). Dieu existe, je L'ai recontré. París: Librairie Arthème Fayard.
García Morente, M. (2002). El "Hecho Extraordinario". Madrid: Rialp.

Gónzalez de Cardedal, O. (1996). Cuatro poetas desde la otra ladera. Valladolid: Trotta.

Haas, A. (2009). Viento de lo absoluto. Madrid: Siruela.

Jankélévitch, V. (2005). La música y lo inefable. Barcelona: Alpha Decay.

Jürgen Baden, H. (1969). Literatura y conversión. Madrid: Guadarrama.

Leiris, M. (2005). Edad de hombre. Precedido de La literatura considerada como una tauromaquia. Pamplona: Laetoli.

Marion, J.-L. (2008). Siendo dado. Madrid: Síntesis.
Martín Velasco, J. (1995). La experiencia cristiana de Dios. Valladolid: Trotta.

Martínez de Burgos, M. (ed.) (1962). El cántico espiritual, según el manuscrito de las madres carmelitas de Jaén. Madrid: Espasa-Calpe.

San Juan de la Cruz (1992). Poesía. Madrid: Cátedra.

Valente, J. Á. (2000). La piedra y el centro. Barcelona: Tusquets.

Wittgenstein, L. (2004). Investigaciones filosóficas. Barcelona: Crítica.

Wittgenstein, L. (2010). Tractatus logicusphilosophicus. Madrid: Alianza. 